[MANUSCRIPT UNDER REVIEW]

\title{
The Happy-Fish-Little-Pond Effect on Enjoyment: Generalizability Across Multiple Domains and Countries
}

\author{
Geetanjali Basarkod ${ }^{1}$, Herbert W. Marsh ${ }^{1}$, Jiesi Guo ${ }^{1}$, Philip Parker ${ }^{1}$, Theresa Dicke ${ }^{1}, \&$ \\ Reinhard Pekrun ${ }^{1,2,3}$ \\ ${ }^{1}$ Institute for Positive Psychology and Education, Australian Catholic University \\ ${ }^{2}$ Department of Psychology, University of Essex \\ ${ }^{3}$ Department of Psychology, Ludwig-Maximilian University Munich
}

\begin{abstract}
Author Note
Corresponding Author: Geetanjali Basarkod, Institute for Positive Psychology and Education, Australian Catholic University, L9, 33 Berry Street, North Sydney, 2060, Australia; geetanjali.basarkod@acu.edu.au;+61297014741.

Declarations of Interest: None

Funding: This research did not receive any specific grant from funding agencies in the public, commercial, or not-for-profit sectors.
\end{abstract}

This manuscript has not been peer-reviewed.

It is currently under review and, therefore, may be subject to change. 


\begin{abstract}
Achievement emotions are important educational constructs. They predict outcomes such as students' achievement, persistence, and drop-out intentions. Thus, it is crucial to examine the factors that determine these emotions. In this study, we focus specifically on the positive emotion of enjoyment as past research has largely focused on negative emotions such as test anxiety. We explore two potential predictors of enjoyment: individual-student achievement and class-average achievement. Past research has shown student achievement to be a positive predictor of enjoyment, with preliminary evidence suggesting class-average achievement to be a negative predictor of enjoyment (Happy-Fish-Little-Pond Effect; HFLPE). However, research has largely been restricted to single-country or single-domain examinations with samples of secondary school students, limiting the generalizability of findings. To bridge this gap, we utilize combined data from the Progress in International Reading Literacy Study (PIRLS) and the Trends in International Mathematics and Science Study (TIMSS) 2011. This sample consisted of 180,084 4th-grade students from 37 countries, with all students responding to items in the math, science, and reading domains. Through multilevel modeling, we demonstrate that the effect of student achievement on enjoyment is positive in all three domains, while the effect of class achievement is negative - confirming the HFLPE. We also demonstrate the relative universality of these results across the 37 countries; while there was variation in the size of the effects, results were largely consistent in direction. Our findings add to the literature on achievement emotions by highlighting two important predictors of enjoyment that operate across domains and crossnationally.
\end{abstract}

Keywords: Achievement emotions; academic enjoyment; happy-fish-little-pond effect; multiple domains; cross-national generalizability 


\section{The Happy Fish Little Pond Effect on Enjoyment: Generalizability Across Multiple Domains and Countries}

Achievement emotions are emotions that are related to achievement activities as well as their success and failure outcomes (Pekrun, 2006). These emotions are closely associated with one's thoughts, behaviors, expressions, arousal, and general day-to-day functioning (Fredrickson, 2001; Pekrun et al., 2017). They are a central component of identity, well-being, and health. Furthermore, achievement emotions have been shown to predict a range of important educational outcomes, such as academic achievement (Pekrun et al., 2017), persistence (Simon et al., 2015), and drop-out intentions (Respondek et al., 2017). They also predict students' twenty-first century skills such as communication, collaboration, critical thinking, and creativity (Camacho-Morles et al., 2021). Thus, not only are achievement emotions important predictors of several crucial outcomes, but they are also essential educational outcomes themselves. Therefore, in this study, we examine constructs that predict achievement emotions.

Past research has shown students' academic achievement to be a principal predictor of achievement emotions (for a meta-analysis, see Camacho-Morles et al., 2021). Achievement is a positive predictor of positive emotions such as enjoyment and a negative predictor of negative emotions such as test anxiety. In addition to the link between student achievement and emotions, however, a recent study also demonstrated the role of context in driving emotions (Pekrun et al., 2019). Specifically, Pekrun et al. showed that while student achievement positively impacts positive emotions and negatively impacts negative emotions, class-level achievement (i.e., the average achievement levels of one's peers) shows the opposite effect. Thus, we focus on these two constructs as potential predictors of emotion.

Traditionally, the vast majority of research on the link between achievement and 
emotions focused on negative emotions, and specifically on test anxiety (Barroso et al., 2021; von der Embse et al., 2018). However, in recent years, research on positive emotions has been steadily increasing (e.g., Pekrun et al., 2017). These studies have tended to focus on emotions within a specific subject domain (e.g., mathematics) and single-country samples (see CamachoMorles et al. 2021 for a meta-analysis). Thus, there is a relative lack of research using multiple domains and countries to examine positive emotions. In the current study, instead of studying a broad array of positive emotions, we take a deep-dive into the examination of just one emotion-

enjoyment. We explore enjoyment across subject domains (math, science, and reading) as well as across 37 countries, using the combined 2011 Progress in International Reading Literacy Study (PIRLS) and Trends in International Mathematics and Science Study (TIMSS) dataset. We examine student- and class-level achievement as predictors of this emotion. In the next section, we describe the importance of enjoyment in education, as well as its links with student- and class-level achievement.

\section{Academic Enjoyment}

\section{Importance of Academic Enjoyment}

Academic enjoyment (henceforth “enjoyment”) represents a key positive emotion that activates cognitive resources for learning, leads to adaptive school outcomes like student engagement (Goetz et al., 2008; Pekrun, 2006), and sustains prolonged goal-oriented behaviors that optimize academic achievement (Camacho-Morles et al. 2021; Fredrickson, 2001; Pekrun et al., 2017). Positive activating emotions like enjoyment can help preserve cognitive resources, facilitate focus of one's attention on the learning task, support interest and intrinsic motivation, while also supporting use of deep learning strategies and promoting students' self-regulation of 
learning (Pekrun et al., 2017). Enjoyment has also been shown to be essential for flow experiences that foster engagement and creative problem solving (Csikszentmihalyi, 2000).

\section{Predictors of Academic Enjoyment}

To explain the predictors of achievement emotions, we draw on control-value theory (CVT; Pekrun, 2006, 2018) as a conceptual framework. CVT is one of the most prominent theories on emotions experienced in achievement and academic contexts. According to CVT, emotions are a consequence of cognitive appraisals of an individual's control over-as well as the subjective value they place on-achievement activities and outcomes. Control appraisals are the individual's perceptions of their ability to successfully perform actions and attain outcomes, while value appraisals are the individual's perception of how important those actions and outcomes are. Thus, successfully performing actions and attaining outcomes that are of value to the individual predicts increased positive emotions (e.g., enjoyment, hope) and reduced negative emotions (e.g., anxiety, hopelessness).

Student-Level Achievement. Enjoyment is said to be instigated if the achievement activity and the material to which it relates are positively valued, and if the activity is perceived to be sufficiently controllable. In other words, a student is more likely to enjoy learning a particular subject when they judge themselves to be competent enough to master that subject, provided they find it valuable and interesting. Thus, high levels of control and value appraisals are proximal antecedents of enjoyment (Pekrun, 2017). Here, we focus more on control appraisals as they are more strongly linked with student achievement (Forsblom et al., 2021; Peixoto et al., 2017), which is a key predictor of concern in this study. 
failure in that subject. Thus, if the student has a history of succeeding in math (e.g., has achieved high math test scores), they will have higher perceptions of control in math, which in turn will lead them to experience positive emotions such as enjoyment (for empirical evidence, see Forsblom et al., 2021). Therefore, a student's level of achievement will predict their level of enjoyment in that subject.

A recent meta-analysis on the link between student achievement and activity-related emotions, which included 57 independent samples for enjoyment, showed that the overall mean true-score correlation between achievement and enjoyment was $.27(95 \% \mathrm{CI}=.23$ to .30 ; Camacho-Morles et al., 2021). While the majority of studies showed a positive association between the two constructs, a handful of studies reported non-significant or negative effects. The sizes of effects tended to vary across domains (math showed a slightly stronger association), education level (samples from secondary school settings showed stronger associations with those from tertiary settings showing the weakest), and country (German samples showed higher associations than Canadian samples). Thus, the results of this meta-analysis suggest that while the link between student achievement and enjoyment is generally positive, there is some variability in its strength.

While meta-analyses are important tools to make inferences about the generalizability of an effect, we note that such studies are limited in relation to the primary studies that they draw upon. This can be an issue because much of the research in psychology tends to utilize samples from Western, educated, industrialized, rich, and democratic (WEIRD) countries. Indeed, the Camacho-Morles et al. meta-analysis relied heavily upon studies conducted in Australia, Canada, Germany, the UK, and the USA. Restricting research to such samples can limit the extent to which we can generalize findings to students from developing countries and varied cultures (see 
Marsh et al., 2020, for a detailed discussion on this issue). Thus, a complementary strategy is to utilize large-scale cross-national samples — as we do here - which comprise a broad range of developed as well as developing countries. Doing so would provide robust evidence regarding the generalizability of results and can supplement the knowledge gained from traditional metaanalyses.

Group-Level Achievement. The role of context in the development of emotions has also been shown to be important. Parents and teachers often believe in the benefits of educating children in selective schools. It is assumed that students attending such schools will have a brighter and more successful future. However, evidence tends to point to the contrary; the average ability level of a class or school has been shown to negatively influence individual students' motivational outcomes, over and above the positive effects of individual-student achievement on these outcomes (Marsh et al., 2020; Pekrun et al., 2019). This has largely been studied in relation to academic self-concept (an individual's perceptions of their own ability; see Basarkod et al., 2022, for an overview), but a recent study has also demonstrated this for achievement emotions including enjoyment (Pekrun et al., 2019).

Put simply, this effect implies that given the same level of individual achievement, students tend to have lower levels of motivational outcomes in high-ability schools than in lowability schools (Parker et al., 2021). Based on CVT, Pekrun et al. hypothesized that, in a class of high achievers, a student's opportunities to be successful relative to others may be relatively low, all else being equal. This is in line with the social comparison theory underlying the negative effect of group-average achievement on self-concept - the Big-Fish-Little-Pond Effect (Marsh \& Parker, 1984). This theory posits that students evaluate their ability not only in relation to their own achievement levels, but also in relation to those around them. Thus, if a student is 
surrounded by peers who achieved top marks in a standardized test, that student is less likely to perceive their own performance as successful. In contrast, if a student is surrounded by peers who achieved low marks, the student will perceive their own score to be a success. Thus, higher class-average achievement is likely to lead to students feeling less in control of the subject, thereby lowering positive emotions and increasing negative emotions (Pekrun et al., 2019). Indeed, Pekrun et al. found that while an individual's performance in their math class was predictive of increased positive emotions about math, the average achievement of that individuals' peers reduced the individual's positive emotions about math. They labeled the negative effect of group-average achievement on students' positive emotions (and positive effect on negative emotions) as the Happy Fish-Little-Pond Effect (HFLPE), after the well-known BigFish-Little-Pond Effect for self-concept (Marsh \& Parker, 1984).

To date, the Pekrun et al. (2019) study is the only one to have examined the HFLPE on student enjoyment. While elucidating another predictor of students' academic emotions (i.e., class-average achievement), the Pekrun et al. (2019) study was limited in generalizability across subject domains and country of assessment. The samples considered were from secondary school math classes in Germany. Thus, it remains to be seen whether the HFLPE on academic emotions extends to subjects other than mathematics, to samples from countries other than Germany, and to primary school students. In recent years, the psychology literature is undergoing a replication crisis; many of the most salient findings in the literature have not been confirmed in subsequent studies and the generalizability of these results is, therefore, questionable. The current study aims to ascertain whether the HFLPE stands up to scrutiny in relation to replication across domains and generalizability across countries. 


\section{Generalizability of Effects}

If evidence for a given theory - the HFLPE in this case-is found in multiple countries and cultural contexts, it can be thought of as a universal principle with pan-human validity (Segall et al., 1998; also see Marsh et al., 2020). CVT assumes that general functional mechanisms of human emotions are universal, but that the specific contents of emotions as well as the specific values of process parameters (such as the intensity of the emotions) may be specific to different individuals or groups of individuals (Pekrun, 2006, 2018). This "relative universality" implies that the functional relations between achievement (both student- and classlevel) and enjoyment are expected to be universal, but that levels of enjoyment may differ across domains and cultural contexts (see Pekrun, 2018, for a summary of supporting evidence). However, no study has yet been conducted regarding the relative universality of the effect of student- and group-level achievement on positive emotions such as enjoyment. In this study, therefore, we examine the effect of both student and group-level achievement on enjoyment across the domains of mathematics, science, and reading, as well as across 37 countries. Given there is no past research on the generalizability of the HFLPE, we briefly review the existing evidence for the effect of student-level achievement on enjoyment across domains and countries below.

\section{Across Domains}

The literature is inconsistent with regard to differences in the sizes of associations between individual-student achievement and enjoyment across domains. While some suggest that the association is similar across domains (Goetz et al., 2008), some show that it is stronger in the math domain (Goetz et al., 2008; Raccanello et al., 2019) and yet others show that it is 
stronger in verbal subjects (Goetz et al., 2012). For instance, Goetz et al. (2008) showed that, in a sample of German students from Grades 5-10, the correlations between math achievement and enjoyment at the item level ranged from .25 to .29 , while the correlations between verbal achievement and enjoyment ranged from .25 to .30 . In a sample of Grade 8-11 students from Germany, Goetz et al. (2012) showed that the correlation between achievement and enjoyment was largest for German (native language; .39 and .30 for class- and homework-related enjoyment, respectively), followed by English (foreign language; .27 and .22 ), physics (.25 and $.20)$, and math (.18 and .14). However, Raccanello et al. (2019) showed different results in a sample of elementary aged students (Grades 2-4). Particularly, the correlation between nativelanguage class enjoyment and native language achievement was .04 and non-significant, while the parallel correlation in the math domain was .19 and significant.

The differences between the results from these studies may be due to differences in sample age. Indeed, the Camacho-Morles et al. (2021) meta-analysis concluded that the overall association between student achievement and enjoyment is moderated by the age of the students; secondary school students show significantly stronger associations than primary school students. Importantly for our study, however, this meta-analysis also showed that the link between achievement and enjoyment was slightly stronger in the math domain (mean true score correlation $=.31)$ compared to other subjects $($ science $=.21 ;$ chemistry $=.25 ;$ psychology $=.15$; other subjects $=.02$ ), though these differences did not reach statistical significance (the only significant difference was between math and psychology).

However, the majority of studies included in the meta-analysis were conducted in the math domain, heavily weighting the findings towards math. There were also not enough primary studies that tested the association between student achievement and enjoyment in the domain of 
reading, to enable an examination of the size of this effect in the reading domain. Our study can address these issues, given that nearly two hundred thousand students responded to the same items about enjoyment in all three domains of math, science, and reading.

\section{Across Countries}

The majority of studies exploring the association between achievement and enjoyment have been restricted to samples from one or two countries. Only a handful of studies have examined the association between achievement and enjoyment across multiple countries (though limited to a single domain). For instance, He et al. (2019) examined the cross-cultural comparability of the association between student achievement and enjoyment in the domain of science, using data from TIMSS 2015 and Programme for International Student Assessment (PISA) 2015. They found that while this association was positive in all 21 developed countries considered, and in both datasets, the size of the correlations varied between .10 and .40 (these numbers are approximate as the results were only plotted on a graph). We note here, however, that the enjoyment measures used by He et al. (2019) from both the TIMSS and the PISA datasets included a scale comprised of items which were not all true measures of enjoyment. For instance, the TIMSS scale of "students like learning science" was used to measure enjoyment, which contained items such as "I wish I did not have to study science", and "Science is boring". These items are not pure enjoyment items, and boredom is an emotion that is different from enjoyment (or the lack thereof; Pekrun et al., 2010). Thus, while there is some past research on this topic, further research is required with clear measures of enjoyment. We build on this past research by utilizing a clear measure of enjoyment in three domains and across 37 countries. Furthermore, beyond student-level links between achievement and enjoyment, we provide the first multi-domain and cross-national examination of the HFLPE. 


\section{The Present Study}

The present study examines the effect of student- and class-level achievement on student enjoyment. We used cross-national data from primary-school aged (Grade 4) students in 37 different countries, responding about their mathematics, science, and reading classes. In 2011, the five-year cycle of the Progress in International Reading Literacy Study (PIRLS)—a largescale international assessment focusing on fourth graders' reading competencies - came into alignment with the four-year cycle of the Trends in International Mathematics and Science Study (TIMSS) — a large-scale international assessment focusing on fourth and eighth graders' math and science competencies - for the first time. Importantly, in 37 countries the same group of fourth-grade students responded to both assessments. This provides an unprecedented opportunity for researchers to merge these two databases and compare fourth graders across three fundamental curricular areas (mathematics, science, and reading) and 37 countries. In addition, the 37 included countries were a mixture of developed and developing countries, providing a better basis of testing generalizability. We use these data in the current study.

The present study provides a novel extension of past research by (i) examining the generalizability of the effects of student- and class-level achievement on student-level enjoyment across math, science, and reading domains; (ii) exploring the cross-national generalizability of these effects across 37 countries; and (iii) studying these effects for a younger sample than has been done previously as past research on the link between achievement and emotions is largely limited to secondary school students. The study aims to answer the following two research questions.

RQ1. Does student-level achievement positively predict student-level enjoyment across subject 
domains and countries?

Based on prior research, we expect student-level achievement to positively predict student-level enjoyment across subject domains (Hypothesis 1) and countries (Hypothesis 2). We leave as an exploratory question if the size of the effects will differ across domains and countries.

RQ2. Does class-level achievement negatively predict student-level enjoyment across subject domains and countries?

We expect class-level achievement to negatively predict student-level enjoyment across subject domains (Hypothesis 3) and countries (Hypothesis 4). While we expect the direction of results to be consistent across domains and countries, we again leave as an exploratory question whether the size of the effects will vary from domain-to-domain and from country-to-country.

\section{Methods}

\section{Data and Participants}

TIMSS is an international assessment of mathematics and science competence in nationally representative samples of fourth- and eighth-grade students. PIRLS is an international assessment of reading comprehension in nationally representative samples of fourth-grade students. In 2011, 37 countries administered the TIMSS and PIRLS assessments to the same samples of fourth-grade students. TIMSS and PIRLS employed a stratified two-stage cluster sample design; in the first stage, schools were randomly selected from the population of schools based on stratification, and in the second stage, classes were sampled at the target level (fourth grade) within the selected schools. Thus, students participating in these datasets largely belonged 
to intact classes. The final sample size used in our analyses included 180,084 students (49.26\% female; Age $M=10.92, S D=0.82$ ) from 8,372 classes and 6,196 schools. The average sample size in each country was 4,867 (range $=2,901$ to 14,449 ; see Supplementary Materials Section 1 , Table S1 for the sample size for each country). We utilize class as our Level 2 cluster variable and country as the Level 3 cluster variable (see Data Analysis section for more detail).

\section{Measures}

\section{Enjoyment}

Student enjoyment in each subject domain was measured by a single item, "I enjoy learning mathematics", "I enjoy learning science", and "I enjoy reading”. Students were asked to rate their agreement with these statements on a 4-point Likert-type scale from 1 (Agree a lot) to 4 (Disagree a lot). Items were reverse-scored such that higher scores indicated greater enjoyment. Past research has shown single items are sufficiently reliable to measure emotions (Gogol et al., 2014).

\section{Achievement}

Student achievement in each subject was measured using five plausible values. To keep student burden to a minimum, TIMSS and PIRLS administered a limited number of items to each student for each subject. Then, plausible values were estimated via models using item response theory to infer students' abilities based on their performance on the items (see Data Analysis section for information on how these plausible values were handled). Class-average achievement was calculated as the average achievement of students in a class (after L1 achievement was grand-mean centered). This average was calculated separately for each plausible value within 
each subject, and then handled the same way as student-level achievement (see Data Analysis section).

\section{Covariates}

In all our models, we controlled for three covariates commonly included in research on compositional effects (Dicke et al., 2018). Socioeconomic status (SES) was assessed with the Home Resources for Learning Scale. This scale was provided in the home background datafile, which contained responses from the students' parents or guardians. The SES score is a composite score based on information about the educational and occupational background of parents, number of books at home, internet access, and whether the student has their own room at home (more information available from the TIMSS-PIRLS website at https://timss.bc.edu/methods/pdf/P11_R_Scales_HRL.pdf). Sex was coded as female $=1$ and male $=2$. Age was assessed using the month and year students were born in, converted to a continuous variable of years.

\section{Data Analysis}

All analyses were conducted in R (Version 3.6.2; R Core Team, 2020), and code has been provided on the Open Science Framework (https://osf.io/kb29h/?view_only=65a45dc5bd9d442eae738bcd0ede87f3). For the purpose of this

study, we merged student and home data using the International Database Analyzer of the International Association for the Evaluation of Educational Achievement (IEA IDB Analyzer). Data were merged at the student level, with each row in the dataset corresponding to one student. In this study, we used data from all 37 countries, for every student who belonged to a class with at least 10 students (to calculate class-average achievement reliably; for a similar procedure, see 
Pekrun et al., 2019). Data was separated by subject, with all analyses run separately on each of these datasets (unless otherwise specified).

The number and percentage of missing cases per variable used in this study are shown in Table 1. Missingness was dealt through multiple imputations using the package Amelia II (Honaker et al., 2011) with Class ID as the clustering variable. Five imputed datasets were created, retaining all variables and covariates mentioned above. We assigned one plausible value for math, science, and reading achievement at the student (L1) and class levels (L2) to each of the five imputed datasets. All analyses were conducted five times, using each imputed dataset once, and results were combined using Rubin's (1987) approach.

Pearson's correlations were calculated for all student-level variables using the miceadds package (Robitzsch et al., 2017), which allows for calculations using multiply imputed data. Owing to the nested structure of the data, continuous variables were group-mean centered using country as the grouping variables for these analyses.

Three-level multilevel models were conducted using lme4 (Bates et al., 2015)—one for each subject domain. In the multilevel models, all student variables were at the student level (L1), except class-average achievement which was a class-level (L2) variable. Random intercepts for class and country were included to account for the clustering of students within classes and classes within countries. Non-categorical L1 variables were standardized across the whole sample (i.e., grand-mean centered). Class-average achievement was calculated after the corresponding L1 achievement variables had been standardized. All models were weighted using the final survey weight for students, normalized for each country (i.e., the sum of the weights in each country was equal to the sample size in that country). All models presented control for the 
covariates of SES, gender, and age.

We interpret the size of the fixed effects from these multilevel models based on recommendations by Else-Quest et al. (2010). They stated that an effect size of less than 0.10 can be considered trivial when sample sizes are large, as estimates of even 0.01 may be statistically significant, and estimates of more than 0.10 as non-trivial. We interpret random effects, and the generalizability of fixed effects across countries, based on recommendations by Marsh (2016). Marsh suggested that there is good support for the generalizability of an a-priori prediction if the standard deviation of country-to-country variation (i.e., the square root of the random variance component) is less than half that of the corresponding fixed-effect estimate in support of that prediction (as the direction of the effect will not change even at extreme values).

To further explore country-to-country variation in the estimates of student- and classachievement on enjoyment, we created forest plots. To do so, we estimated two-level models (L1: student; L2: class) in each country independently (controlling for the covariates). We then extracted estimates and confidence intervals for L1 achievement and L2-average achievement predicting enjoyment, and graphed them in forest plots.

\section{Results}

\section{Descriptive Statistics and Correlations}

Table 1 presents descriptive statistics for all variables included in this study, while Table 2 presents zero-order correlations across the whole sample, using group-centering at the country level. The correlational analyses indicated positive correlations between L1 achievement and enjoyment, for all three domains. We note, however, that while statistically significant (given the 
large sample size), the magnitude of these correlations in the domains of math and science were rather small ( $r=.076$ and .058 , respectively). The correlation was larger for the domain of reading $(r=.183)$. Indeed, reading enjoyment had the largest correlations with all three domains of achievement (i.e., achievement in both matched and non-matched subject domain), compared to the correlations for math and science enjoyment.

\section{Multilevel Analyses}

Table 3 presents results from the three-level models predicting math, science, and reading enjoyment, respectively. These models include student- and class-level achievement as predictors, along with the covariates of SES, gender, and age.

\section{Fixed Effects: Across Domains}

The fixed effect estimates show that domain-specific student-level achievement positively predicted student-level enjoyment in each of the three subject domains, confirming Hypothesis 1 . This predictive effect was largest for reading enjoyment $(\beta=.240)$, followed by math $(\beta=.167)$, and smallest for science enjoyment $(\beta=.097)$. As hypothesized, the direction generalized over domains even though the size of the effects varied. Class-level achievement negatively predicted student-level enjoyment in all three domains, confirming Hypothesis 3. There was a larger effect for math enjoyment $(\beta=-.171)$, followed by science $(\beta=-.121)$ and reading enjoyment $(\beta=-.073)$. While there was a negative significant effect for reading enjoyment, we note that the size of this effect may be considered trivial as it was smaller than 0.10 (Else-Quest et al., 2010). Overall, results showed that while students with higher achievement levels showed greater enjoyment levels in that domain, students in classes with higher class-average achievement showed lower levels of enjoyment in that domain. Thus, while 
the effect was negative in all three domains, the size of this effect again varied. This confirms the HFLPE for enjoyment in our data, across all three domains (though the effect size in the reading domain may be considered trivial).

\section{Random Effects: Across Countries}

Following recommendations from Marsh (2016), results indicate that the effect of student achievement on enjoyment is generalizable across countries for the domain reading. That is, the standard deviations at the country level for math $(S D=.081)$ and reading enjoyment $(S D=.109)$ were less than half the corresponding fixed estimate (math: $\beta=.167$; reading: $\beta=.240$ ). While there was a positive predictive effect of science achievement on science enjoyment, the findings suggest that this effect is likely to be less consistent across countries $(\beta=.097, S D=.067)$. In terms of the effect of class-average achievement, results show that there was substantial variation across countries, in relation to the size of the fixed effects. That is, for all three domains, the standard deviation was larger than half the size of the corresponding fixed effect (math: $\beta=$ $.171, S D=.103$; science: $\beta=-.121, S D=.079$; reading: $\beta=-.073, S D=.121)$. Thus, while there is an overall trend of a HFLP for all three domains, the size of the effect varies from country to country.

\section{Forest Plots: Across Countries}

We further explore the variation across countries through forest plots. Figure 1 presents forest plots for the effects of student-level achievement on enjoyment in each of the three subject domains, in each of the participating countries. Figure 2 presents parallel forest plots for the effect of class-average achievement. The exact estimates and standard errors for each country are presented in the Supplementary Materials (Section 2; Tables S2 and S3). 
In terms of student-level achievement, all significant effects were positive in all three domains. The estimate was non-significant for two countries in the math domain, and for thirteen countries in the science domain (with three of these non-significant effects in the negative direction). All effects were significant and positive in the reading domain. Thus, even though there were large standard deviations in comparison to the fixed effects for the science domain, these forest plots show that the effect of student achievement on enjoyment was largely consistently positive across countries, for all three domains. In addition, the average effects from these models were similar to those from the multilevel models (math: $\beta=.163, S E=.013$; science: $\beta=.092, S E=.011$; reading: $\beta=.233, S E=.017)$. This confirms our Hypothesis 2 ; the effect of student achievement on enjoyment is positive across countries with variation in the size of this effect.

For class-level achievement, for both math and science enjoyment, all significant effects were negative, and non-significant effects were mostly negative. While the pattern was largely similar for reading enjoyment, four effects were significantly positive. Thus, especially for the domains of math and science, while the standard deviation was more than half the size of the fixed effect for class-average achievement, the forest plots demonstrate that this variation was largely in the size of the effect rather than in its direction. Again, the average effects from these models were similar to those from the multilevel models (math: $\beta=-.145, S E=.020$; science: $\beta$ $=-.107, S E=.019$; reading: $\beta=-.059, S E=.022)$. This largely confirms our Hypothesis 4 . That is, the effects of class-average achievement on enjoyment were mostly negative and the size of the negative effect varied from country-to-country. 


\section{Discussion}

Academic enjoyment is an important educational outcome. A greater understanding of the predictors of academic enjoyment would enable the development of interventions to positively impact enjoyment, which would in turn positively promote increased achievement and other academic outcomes (Bieg et al., 2013; Buff, 2014; Luo et al., 2016). The primary aim of this study was, therefore, to examine two main predictors of academic enjoyment - student-level achievement and class-level achievement — as well as the relative universality of these effects across three subject domains and 37 countries. Our results demonstrated that while student-level achievement positively predicted student enjoyment, the effect of class-level achievement was negative. The pattern of these results was consistent across the domains of math, science, and reading, and largely consistent across the 37 countries included in the TIMSS-PIRLS 2011 sample.

Our study extended previous research in two important ways. First, there has been no prior research exploring the multi-domain and cross-national generalizability of the predictive effect of student-level achievement on academic enjoyment. Previous research in this field has largely focused on the negative emotion of anxiety, and has been limited to a single subject domain or a single country. Indeed, in the PISA publications, the OECD provides detailed reports about test anxiety and math anxiety (e.g., OECD, 2018). Thus, we extend prior research by exploring the association between achievement and the positive emotion of enjoyment. Second, there has only been one previous study positing and testing the HFLPE on enjoyment; this study was limited to the domain of math in samples of students from Germany (Pekrun et al., 2019). Thus, our study extends prior research by examining the HFLPE for the domains of science and reading in addition to mathematics. Moreover, we included samples from 36 
countries in addition to Germany, and demonstrated how the effects of both student and classlevel achievement on enjoyment are relatively robust across countries.

\section{Student-Level Achievement and Enjoyment}

While there is some inconsistency in the literature, past research has shown that students' enjoyment for a given subject is usually positively related to achievement within the same domain (Camacho-Morles et al., 2021). Much of the past research on this topic has considered enjoyment (and, indeed, emotions in general) as a predictor of achievement. Students who enjoy a particular subject tend to be more engaged with the materials and channel their cognitive efforts to the activity at hand, thereby performing better. However, recent research has also shown that prior achievement leads to enjoyment (e.g., Forsblom et al., 2021; Pekrun et al., 2017). While cross-sectional, our study is consistent with such findings, as we show that achievement positively predicts enjoyment in matched subject domains. Thus, the better a student performs at a given subject, the more they tend to enjoy it.

We note that the L1 effects shown in our study are generally smaller than the mean effects reported in the meta-analysis by Camacho-Morles et al. (2021). Indeed, Camacho-Morles et al. showed that the effect was stronger in secondary school samples than primary school samples. As the students in our sample are mostly in Grade 4, this may explain the smaller effects of student achievement on enjoyment seen in our study. This difference between primary and secondary school samples may be because repeated feedback about achievement over a longer period creates a stronger link between performance and emotions. Thus, students in secondary school have longer to gain knowledge about their level of achievement than students in primary school and, thus, may demonstrate stronger associations between their achievement 
and enjoyment levels. Our study provides an important addition to the literature on achievement emotion by extending past research to primary school students.

\section{Class-Level Achievement and Enjoyment}

Our results showed that, in general, class-average achievement had a negative effect on students' enjoyment. This means that a student would have lower levels of enjoyment in a class with higher class-average achievement than if they were in a class with lower class-average achievement. This finding can also be understood in terms of CVT, in combination with social comparison processes that usually operate for the Big-Fish-Little-Pond effect (Marsh \& Parker, 1984). Put simply, in a class with high-achieving peers, a student would have less opportunities for success and would feel reduced control over the subject material, which would thereby reduce the amount of enjoyment felt by the student. We evaluate our ability not only in relation to our own achievement levels, but also in relation to those around us. Our peers' achievement acts as a frame of reference for the judgements we make about our own ability. Such a social comparison process indicates that a student would evaluate their ability to be greater when they perform better than those around them. If they achieved top marks when their peers achieved average marks, they would feel more successful and more in control of the subject material, than if their peers also achieved top marks. Thus, the higher the class-average achievement, the lower the student's perception of their ability. This in turn implies lower levels of control over the subject material, which is associated with lower levels of enjoyment in relation to the subject.

Our results are again smaller in magnitude compared to the only previous study on the HFLPE (Pekrun et al., 2019). Pekrun et al.'s study demonstrated that the effect of class-average achievement on enjoyment was -.40 — an effect size much larger than the overall estimate 
reported here. However, there are two important distinctions between our study and the Pekrun et al. (2019) study that might help explain the difference. The Pekrun et al. study was conducted only in the domain of math and only in the country of Germany. Therefore, the comparable beta estimate in our study is the one for the domain of math in Germany. This estimate was -.47, which is largely comparable to that reported in the Pekrun et al. study. Our study builds on this past research to provide a better estimate of the generalizable effect of group-average achievement on student enjoyment.

\section{Generalizability of Results}

As mentioned in the Introduction, Pekrun (2006) stated that the processes underlying the formation of academic emotions and their consequences operate according to relative universality. That is, the processes themselves are the same for everyone (i.e., universal). However, the degree to which these processes operate varies from person to person, depending on their context (i.e., is relative). The results of this study are largely consistent with this proposition. Specifically, the effect of student-level achievement on enjoyment was largely positive across domains and countries, but the size of this effect varied. Similarly, the effect of class-average achievement on student enjoyment was mostly negative across domains and countries (with some exceptions), but the specific size of this effect varied. Thus, our results generally support the relative universality principle.

\section{Across Domains}

The effect of student-level achievement on enjoyment was the strongest in the reading domain, followed by the math domain, and finally the science domain. In contrast, the effect of class-average achievement was the strongest in the math domain, followed by the science 
domain, and finally the reading domain. The contrasting results for the reading domain are likely due to the way enjoyment was measured. For the math and science domains, the item asked students whether they enjoyed learning math/science. In contrast, in the reading domain the item simply asked whether students "enjoyed reading". Thus, for the reading domain, the enjoyment item was not specific to the school context, but rather assessed reading enjoyment in general.

In terms of the effects of student-level achievement, it is possible that the stronger effect for the reading domain was because students who are good at reading likely also read outside of school for enjoyment, thus strengthening the link between reading competency and enjoyment through frequent positive reading experiences. In terms of the effects of class-average achievement, the lack of focus on the school context reduces the likelihood of the social comparison process operating in the students' judgment of their enjoyment (Marsh et al., 2019). As such, it is less likely that the achievement of peers played a role in students' responses to the enjoyment items. In contrast, as the math and science items were specific to the learning context, it is more likely that the achievement of peers played a role here. Thus, the frame-of-reference effect of class-average achievement was less relevant for the reading enjoyment item than for the enjoyment items in the math and science domains.

Past research has suggested that relations of achievement and enjoyment tend to be stronger in math compared to other subjects such as reading and science (Camacho-Morles et al., 2021; Goetz \& Hall, 2013). Our research is in opposition to these findings. This may also be due to the lack of education-context information in the items, as mentioned above. However, it must also be noted that the Camacho-Morles et al. meta-analysis was heavily weighted towards math, and therefore, had lesser information about the association between achievement and enjoyment in the domains of science and especially reading. A consequence is the smaller aggregate 
samples in non-math domains, and thus a greater probability for second-order sampling error (Hunter \& Schmidt, 2004) which lessens the power of the analysis. Goetz and Hall (2013) noted that the association between achievement and enjoyment is greater when both are measured at the same level of temporal granularity. TIMSS and PIRLS assessed enjoyment at the trait level. Such measures would have larger associations with measures of cumulative achievement, rather than with one-off assessments such as those used in TIMSS and PIRLS. Thus, it is likely that the effect of achievement on enjoyment would have been even greater had such cumulative achievement measures been used.

\section{Across Countries}

The effect of student-level achievement on enjoyment showed relative universality across countries. While this effect was consistently positive across all countries, the size of the effect varied. Thus, in general, students who had high levels of achievement also tended to show greater levels of enjoyment. However, the extent to which these students showed higher levels of enjoyment differed across countries. Similarly, the effect of class-average achievement on enjoyment was negative in most countries, with variation in the size of this effect. Given the same level of student-level achievement, students in classes with high average levels of achievement tended to show lower levels of enjoyment. However, the extent to which classaverage achievement affected students' enjoyment differed across countries.

As mentioned earlier, CVT proposes that student achievement positively predicts enjoyment because of increased perceived control over the subject matter, and that higher classaverage ability reduces this sense of control (Pekrun, 2006; Pekrun et al., 2019). Given the consistency of the direction of effects across countries, our findings suggest that these processes 
underlying the two effects are likely similarly across countries. This is an important finding given that the samples used in this study are not just restricted to WEIRD countries, thus providing a strong basis for replicability and generalizability of results.

We do note that there are a few exceptions to this general pattern of findings, especially for the HFLPE in the reading domain. As mentioned earlier, this could be due to the lack of class-context in the measure of reading enjoyment. Still, future research is required to ascertain what is different, if anything, about the very few countries that showed non-significant effects or effects in the opposite direction to the general trend. Future research is also required to examine why differences in the size of the effects across countries (and domains) occur, and whether these differences can be explained through country-level differences in educational systems or policies.

\section{Limitations, Directions for Future Research, and Practical Implications}

While we consider enjoyment as an outcome in this study, it is important to note that causality cannot be determined in a cross-sectional study. Indeed, there is evidence to suggest that the links between achievement and enjoyment are reciprocal (Forsblom et al., 2021; Pekrun et al., 2017). For instance, in a study of secondary students from Germany, Pekrun et al. (2017) showed positive and significant path estimates from prior achievement to subsequent enjoyment as well as from prior enjoyment to subsequent achievement. Forsblom et al. (2021) demonstrated the same pattern of results in a sample of 5 th and 7 th grade students from Portugal. Thus, increases in achievement lead to increases in enjoyment and vice versa. Unfortunately, there is a dearth of cross-national datasets that are also longitudinal in nature. While such a dataset would be ideal for future research, we can currently only amalgamate the knowledge we have from 
research using cross-national, cross-sectional data with research using single-country, longitudinal data. Thus, our study adds to past longitudinal research on the effect of student and class-average achievement on enjoyment by examining these relations across multiple countries.

Future research is required to ascertain the mediating role of control and value on the effect of achievement on enjoyment based on a longitudinal design. According to CVT, enjoyment is instigated when a student feels in control of the task at hand and perceives the activity to be valuable. This would imply that self-perceptions of control and of competence, such as academic self-concept, are mediators in the link between achievement and enjoyment. There is some preliminary evidence supporting this proposition. Forsblom et al. (2021) tested the mediating role of perceived control in the relationship between math achievement and enjoyment. Using data from a longitudinal study with a sample of Portuguese students, Forsblom et al. demonstrated that there was an indirect effect of math achievement on math enjoyment mediated by perceived control. Specifically, they showed that prior achievement positively predicted perceived control, which in turn positively predicted subsequent enjoyment. Thus, the association between achievement and enjoyment is at least partially mediated by a student's sense of control over the subject material.

Our study was also limited in relation to the breadth of emotions covered, as we focused specifically on the positive emotion of enjoyment. Past research has shown that student-level achievement is positively and reciprocally related to various positive emotions, and negatively and reciprocally related to negative emotions (Pekrun et al., 2017). Similarly, the effect of groupaverage achievement is negative for positive emotions and positive for negative emotions (Pekrun et al., 2019). Thus, in line with the findings of our study, we would expect a similar pattern of relations with other positive emotions across domains and countries, and the opposite 
pattern for negative emotions. In line with relative universality (Pekrun 2006), however, research would need to attend to possible variation of these effects across contexts.

We also note that our study utilized single-item measures of enjoyment. While past research suggests that it is appropriate and reliable to utilize single-item measures (Gogol et al., 2014), there are issues of measurement error that are better dealt with using multiple-item scales. However, care is required when using multiple-item measures as all items in the scale might not measure the same emotion. For instance, as noted earlier, measures that assess enjoyment and boredom within the same scale tend to confound two different emotions. Thus, future research is required to confirm our results using multiple-item measures of enjoyment that are true measures of this construct.

Despite these limitations, our findings were robust across domains and countries, and thus, have large-scale implications for policy and practice. Interventions aimed at increasing beneficial emotions such as enjoyment, could focus on designing classrooms that maximize the positive effects of student-level achievement and reduce the impact of peer-group achievement. This could be done by providing students with opportunities for success, not just in relation to their own achievement but also in relation to their peers. In addition, the negative effect of classlevel achievement on enjoyment also suggests that selective schooling-where students are chosen based on their high achievement levels thereby increasing the average achievement levels of the group - may harm students' academic enjoyment. Given the generalizability of our results, these implications may be relevant for multiple subjects and across different socio-cultural contexts as represented by different countries. 


\section{Conclusion}

We demonstrate the relative universality of positive effects of individual student achievement, and negative effects of class-average achievement, on academic enjoyment. We do so across the subject domains of mathematics, science, and reading, as well as across 37 countries. Our findings add to the literature on achievement emotions by highlighting two important predictors of enjoyment that operate across domains and cross-nationally.

Interventions aimed at increasing positive academic emotions such as enjoyment can, thus, focus on increasing student-level achievement while also increasing opportunities for success in relation to students' peer groups. 


\section{References}

Barroso, C., Ganley, C. M., McGraw, A. L., Geer, E. A., Hart, S. A., \& Daucourt, M. C. (2021). A meta-analysis of the relation between math anxiety and math achievement. Psychological Bulletin, 147(2), 134-168. https://doi.org/10.1037/bul0000307

Basarkod, G., Marsh, H. W., Dicke, T., Guo, J., \& Parker, P. D. (2022). A Key Construct for Positive Psychology. In K. Allen, M. J. Furlong, D. Vella-Brodrick, \& S. M. Suldo (Eds.), Handbook of Positive Psychology in Schools: Supporting Process and Practice (pp. 202-216). Routledge. https://doi.org/10.4324/9781003013778-15

Bates, D., Maechler, M., Bolker, B., Walker, S., Christensen, R. H. B., Singmann, H., Dai, B., Grothendieck, G., Green, P., \& Bolker, M. B. (2015). Package 'lme4’. Convergence, 12(1), 2.

Bieg, M., Goetz, T., \& Hubbard, K. (2013). Can I master it and does it matter? An intraindividual analysis on control-value antecedents of trait and state academic emotions. Learning and Individual Differences, 28, 102-108.

https://doi.org/10.1016/j.lindif.2013.09.006

Buff, A. (2014). Enjoyment of learning and its personal antecedents: Testing the change-change assumption of the control-value theory of achievement emotions. Learning and Individual Differences, 31, 21-29. https://doi.org/10.1016/j.lindif.2013.12.007

Camacho-Morles, J., Slemp, G. R., Pekrun, R., Loderer, K., Hou, H., \& Oades, L. G. (2021). Activity achievement emotions and academic performance: A meta-analysis. Educational Psychology Review, 33(3), 1051-1095. https://doi.org/10.1007/s10648-020-09585-3 
Csikszentmihalyi, M. (2000). The contribution of flow to positive psychology. American Psychological Association

Dicke, T., Marsh, H. W., Parker, P. D., Pekrun, R., Guo, J., \& Televantou, I. (2018). Effects of school-average achievement on individual self-concept and achievement: Unmasking phantom effects masquerading as true compositional effects. Journal of Educational Psychology, 110(8), 1112-1126. https://doi.org/10.1037/edu0000259

Else-Quest, N. M., Hyde, J. S., \& Linn, M. C. (2010). Cross-national patterns of gender differences in mathematics: a meta-analysis. Psychological Bulletin, 136(1), 103. https://doi.org/10.1037/a0018053

Forsblom, L., Pekrun, R., Loderer, K., \& Peixoto, F. (2021). Cognitive appraisals, achievement emotions, and students' math achievement: A longitudinal analysis. Journal of Educational Psychology, 114(2), 346-367. https://doi.org/10.1037/edu0000671

Fredrickson, B. L. (2001). The role of positive emotions in positive psychology: The broadenand-build theory of positive emotions. American Psychologist, 56(3), 218-226. https://doi.org/10.1037/0003-066X.56.3.218

Goetz, T., Frenzel, A. C., Hall, N. C., \& Pekrun, R. (2008). Antecedents of academic emotions: Testing the internal/external frame of reference model for academic enjoyment. Contemporary Educational Psychology, 33(1), 9-33. https://doi.org/10.1016/j.cedpsych.2006.12.002 
Goetz, T., \& Hall, N. C. (2013). Emotion and achievement in the classroom. In J. Hattie \& E. M. Anderman (Eds.), International guide to student achievement (pp. 192-195). Routledge/Taylor \& Francis Group.

Goetz, T., Nett, U. E., Martiny, S. E., Hall, N. C., Pekrun, R., Dettmers, S., \& Trautwein, U. (2012). Students' emotions during homework: Structures, self-concept antecedents, and achievement outcomes. Learning and Individual Differences, 22(2), 225-234. https://doi.org/10.1016/j.lindif.2011.04.006

Gogol, K., Brunner, M., Goetz, T., Martin, R., Ugen, S., Keller, U., Fischbach, A., \& Preckel, F. (2014). "My questionnaire is too long!" The assessments of motivational-affective constructs with three-item and single-item measures. Contemporary Educational Psychology, 39(3), 188-205. https://doi.org/10.1016/j.cedpsych.2014.04.002

He, J., Barrera-Pedemonte, F., \& Buchholz, J. (2019). Cross-cultural comparability of noncognitive constructs in TIMSS and PISA. Assessment in Education: Principles, Policy \& Practice, 26(4), 369-385. https://doi.org/10.1080/0969594X.2018.1469467

Honaker, J., King, G., \& Blackwell, M. (2011). Amelia II: A program for missing data. Journal of Statistical Software, 45, 1-47. https://doi.org/10.18637/jss.v045.i07

Hunter, J. E., \& Schmidt, F. L. (2004). Methods of meta-analysis: Correcting error and bias in research findings. Sage. 
Luo, W., Ng, P. T., Lee, K., \& Aye, K. M. (2016). Self-efficacy, value, and achievement emotions as mediators between parenting practice and homework behavior: A controlvalue theory perspective. Learning and Individual Differences, 50, 275-282. https://doi.org/10.18637/jss.v045.i07

Marsh, H. W. (2016). Cross-cultural generalizability of year in school effects: Negative effects of acceleration and positive effects of retention on academic self-concept. Journal of Educational Psychology, 108(2), 256-273. https://doi.org/10.1037/edu0000059

Marsh, H. W., \& Parker, J. W. (1984). Determinants of student self-concept: Is it better to be a relatively large fish in a small pond even if you don't learn to swim as well? Journal of Personality and Social Psychology, 47(1), 213-231. https://doi.org/10.1037/00223514.47.1.213

Marsh, H. W., Parker, P. D., Guo, J., Pekrun, R., \& Basarkod, G. (2020). Psychological Comparison Processes and Self-Concept in Relation to Five Distinct Frame-OfReference Effects: Pan-Human Cross-Cultural Generalizability over 68 Countries. European Journal of Personality, 34(2), 180-202. https://doi.org/10.1002/per.2232

Marsh, H. W., Pekrun, R., Parker, P. D., Murayama, K., Guo, J., Dicke, T., \& Arens, A. K. (2019). The murky distinction between self-concept and self-efficacy: Beware of lurking jingle-jangle fallacies. Journal of Educational Psychology, 111(2), 331-353. https://doi.org/10.1037/edu0000281

OECD (2018) PISA 2015: Results in Focus. OECD. Retrieved from https:/www.oecd.org/pisa/pisa-2015-results-in-focus.pdf 
Parker, P., Dicke, T., Guo, J., Basarkod, G., \& Marsh, H. (2021). Ability stratification predicts the size of the big-fish-little-pond effect. Educational Researcher, 50(6), 334-344. https://doi.org/10.3102/0013189X20986176

Peixoto, F., Sanches, C., Mata, L., \& Monteiro, V. (2017). "How do you feel about math?”: Relationships between competence and value appraisals, achievement emotions and academic achievement. European Journal of Psychology of Education, 32(3), 385-405. https://doi.org/10.1007/s10212-016-0299-4

Pekrun, R. (2006). The control-value theory of achievement emotions: Assumptions, corollaries, and implications for educational research and practice. Educational Psychology Review, 18(4), 315-341. https://doi.org/10.1007/s10648-006-9029-9

Pekrun, R. (2018). Control-value theory: A social-cognitive approach to achievement emotions. Big Theories Revisited, 2, 162-190.

Pekrun, R., Goetz, T., Daniels, L. M., Stupnisky, R. H., \& Perry, R. P. (2010). Boredom in achievement settings: Exploring control-value antecedents and performance outcomes of a neglected emotion. Journal of Educational Psychology, 102(3), 531-549. https://doi.org/10.1037/a0019243

Pekrun, R., Lichtenfeld, S., Marsh, H. W., Murayama, K., \& Goetz, T. (2017). Achievement emotions and academic performance: Longitudinal models of reciprocal effects. Child Development, 88(5), 1653-1670. https://doi.org/10.1111/cdev.12704 
Pekrun, R., Murayama, K., Marsh, H. W., Goetz, T., \& Frenzel, A. C. (2019). Happy fish in little ponds: Testing a reference group model of achievement and emotion. Journal of Personality and Social Psychology, 117(1), 166-185.

https://doi.org/10.1037/pspp0000230

Raccanello, D., Brondino, M., Moè, A., Stupnisky, R., \& Lichtenfeld, S. (2019). Enjoyment, boredom, anxiety in elementary schools in two domains: Relations with achievement. The Journal of Experimental Education, 87(3), 449-469. https://doi.org/10.1080/00220973.2018.1448747

Respondek, L., Seufert, T., Stupnisky, R., \& Nett, U. E. (2017). Perceived academic control and academic emotions predict undergraduate university student success: Examining effects on dropout intention and achievement. Frontiers in Psychology, 8, 243. https://doi.org/10.3389/fpsyg.2017.00243

R Core Team. (2020). R: A language and environment for statistical computing. R Foundation for Statistical Computing. Retrieved from https://www.R-project.org/

Robitzsch, A., \& Grund, S. (2020). miceadds: Some Additional Multiple Imputation Functions, Especially for 'mice' (version 3.10-28). https://CRAN.R-project.org/package=miceadds.

Rubin, D. B. (1987). Multiple imputation for nonresponse in surveys. John Wiley \& Sons. https://doi.org/10.1002/9780470316696

Segall, M. H., Lonner, W. J., \& Berry, J. W. (1998). Cross-cultural psychology as a scholarly discipline: On the flowering of culture in behavioral research. American Psychologist, 53(10), 1101-1110. https://doi.org/10.1037/0003-066X.53.10.1101 
Simon, R. A., Aulls, M. W., Dedic, H., Hubbard, K., \& Hall, N. C. (2015). Exploring student persistence in STEM programs: a motivational model. Canadian Journal of Education, $38(1), 1-27$.

von der Embse, N., Jester, D., Roy, D., \& Post, J. (2018). Test anxiety effects, predictors, and correlates: A 30-year meta-analytic review. Journal of Affective Disorders, 227, 483-493. https://doi.org/10.1016/j.jad.2017.11.048 


\section{Table 1}

Descriptive Statistics for the Study Variables

\begin{tabular}{lcc}
\hline Variable & Mean $(S D)$ & n Missing (\%) \\
\hline Enjoyment & $3.40(0.89)$ & $4,640(2.58 \%)$ \\
Math & $3.52(0.82)$ & $5,497(3.05 \%)$ \\
Science & $3.40(0.91)$ & $4,889(2.71 \%)$ \\
Reading & & $0(0 \%)$ \\
L1 Achievement & $478(111)$ & $0(0 \%)$ \\
Math & $473(121)$ & $0(0 \%)$ \\
Science & $474(117)$ & \\
Reading & & $0(0 \%)$ \\
L2 Achievement & $n(\%)$ & $0(0 \%)$ \\
Math & $473(93)$ & $0(0 \%)$ \\
Science & $474(90)$ & $21,310(11.83 \%)$ \\
Reading & $9.95(2.03)$ & $452(0.25 \%)$ \\
SES & $10.29(0.82)$ & $3(0.002 \%)$ \\
Age & $91,369(51 \%)$ & \\
Gender & & \\
Female & & \\
Male & & \\
\hline
\end{tabular}

Note. Achievement scores here use the first plausible value and all descriptives are based on raw, unimputed data. Total sample size $=180,084$. 
Table 2

Correlations Between Level 1 Variables

\begin{tabular}{|c|c|c|c|c|c|c|c|c|c|c|}
\hline & & 1 & 2 & 3 & 4 & 5 & 6 & 7 & 8 & 9 \\
\hline 1 & Math Enjoyment & - & & & & & & & & \\
\hline 2 & Science Enjoyment & .153 & - & & & & & & & \\
\hline 3 & Reading Enjoyment & .182 & .256 & - & & & & & & \\
\hline 4 & Math Achievement & .076 & .021 & .117 & - & & & & & \\
\hline 5 & Science Achievement & .035 & .058 & .143 & .839 & - & & & & \\
\hline 6 & Reading Achievement & .016 & .056 & .183 & .783 & .851 & - & & & \\
\hline 7 & SES & -.019 & .013 & .096 & .329 & .346 & .342 & - & & \\
\hline 8 & Age & -.008 & -.016 & -.035 & -.050 & -.054 & -.056 & -.112 & - & \\
\hline 9 & Gender & .050 & -.008 & -.178 & .007 & -.007 & -.119 & -.011 & .049 & - \\
\hline
\end{tabular}

Note. Correlations were calculated using all 5 imputed datasets and combined using Rubin's rules. All correlations are statistically significant $(p<.05)$. 


\section{Table 3}

Results From Multilevel Models Predicting Enjoyment

\begin{tabular}{|c|c|c|c|c|c|c|}
\hline & \multicolumn{2}{|c|}{ Math } & \multicolumn{2}{|c|}{ Science } & \multicolumn{2}{|c|}{ Reading } \\
\hline & $\beta$ & $S E$ & $\bar{\beta}$ & $S E$ & $\beta$ & $S E$ \\
\hline \multicolumn{7}{|l|}{ Fixed Effects } \\
\hline Intercept & -.214 & .047 & .007 & .039 & .394 & .048 \\
\hline Ach & .167 & .014 & .097 & .012 & .240 & .018 \\
\hline L2 Ach & -.171 & .020 & -.121 & .017 & -.073 & .024 \\
\hline SES & -.031 & .003 & .011 & .003 & .057 & .003 \\
\hline Gender & .111 & .005 & -.007 & .005 & -.324 & .005 \\
\hline Age & -.009 & .003 & -.014 & .004 & -.019 & .003 \\
\hline \multicolumn{7}{|l|}{ Random Effects (SDs) } \\
\hline Intercept | Class & .243 & & .252 & & .238 & \\
\hline Ach | Class & .096 & & .118 & & .113 & \\
\hline Intercept | Country & .278 & & .229 & & .288 & \\
\hline Ach | Country & .081 & & .067 & & .109 & \\
\hline L2 Ach | Country & .103 & & .079 & & .121 & \\
\hline Residuals & .914 & & .926 & & .913 & \\
\hline
\end{tabular}

Note. Random effects are shown in standard deviations. The labels for these random effects represent the intercept/variable being random at the class and country levels. 


\section{Figure 1}

Country-Wise Estimates and 95\% Confidence Intervals of the Effect of Student-Level Achievement on Enjoyment by Domain

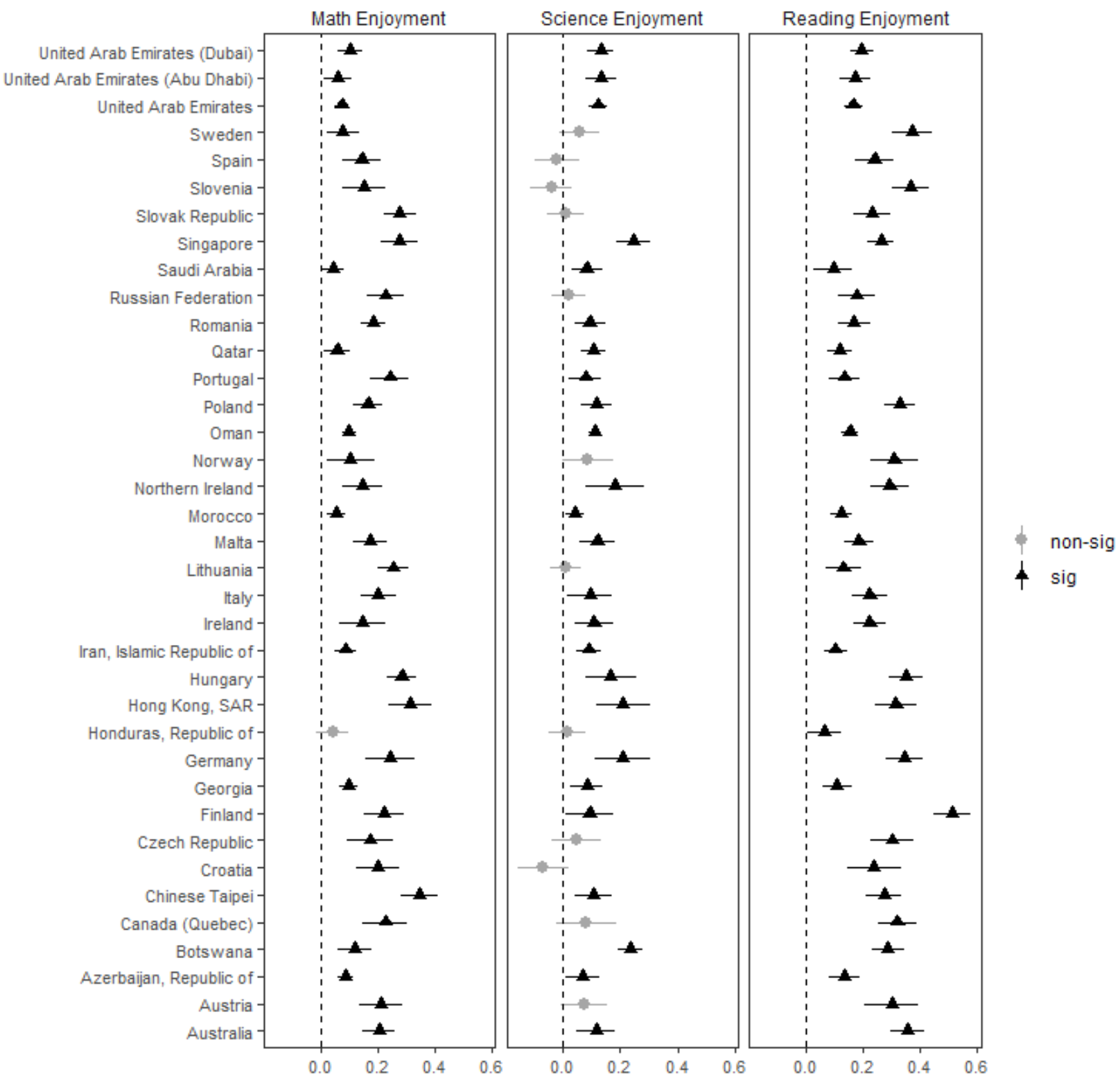


Figure 2

Country-Wise Estimates and 95\% Confidence Intervals of the Effect of Class-Average Achievement on Enjoyment by Domain

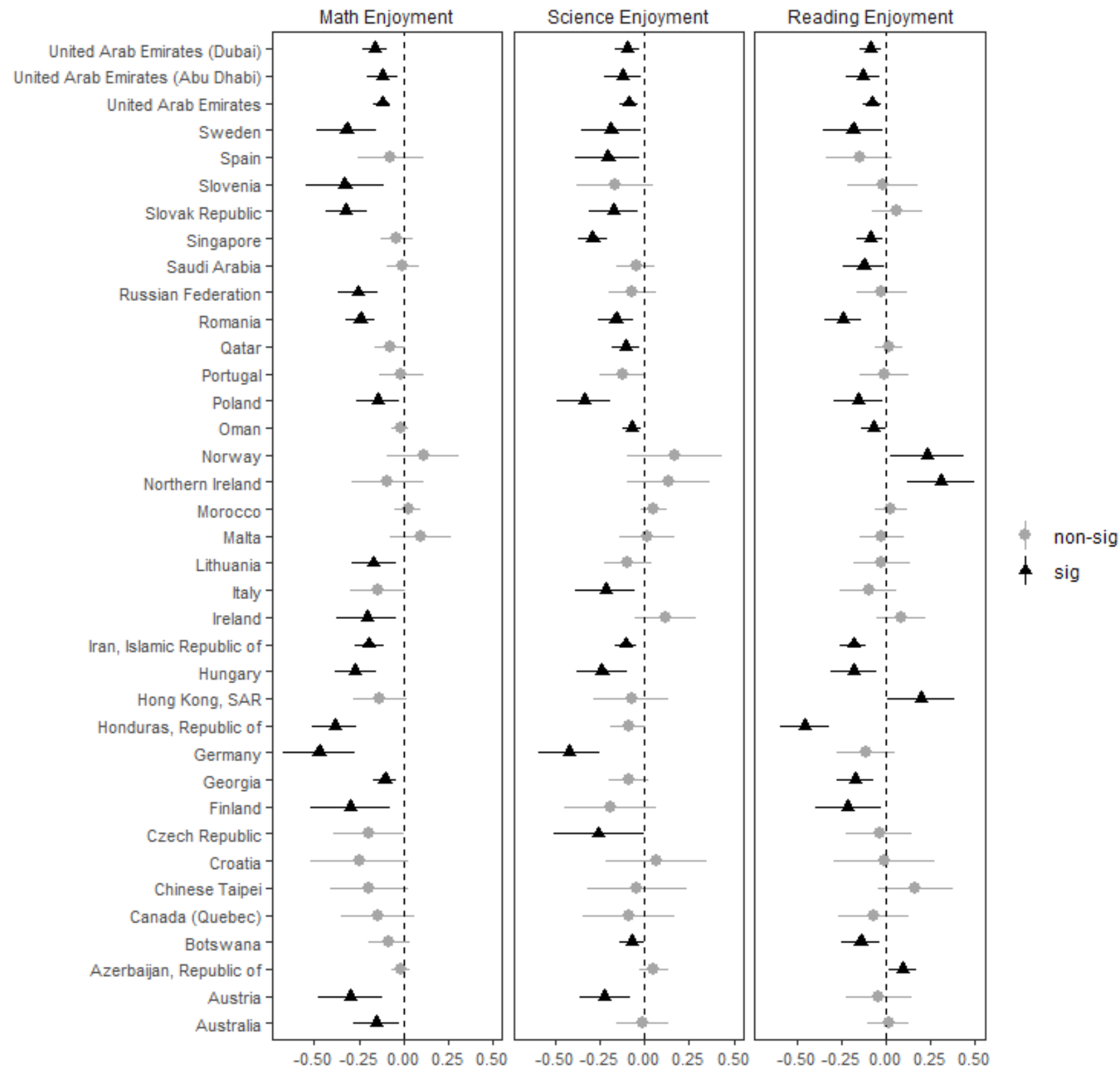


ONLINE SUPPLEMENTARY MATERIALS

\section{Supplementary Materials 1: Country-by-Country Sample Sizes}

\section{Table S1}

Sample Sizes for Each Country in the Combined TIMSS-PIRLS Data

\begin{tabular}{ll}
\hline Country & $\mathrm{n}$ \\
\hline Azerbaijan, Republic of & 4728 \\
Australia & 5186 \\
Austria & 4366 \\
Botswana & 4133 \\
Chinese Taipei & 4265 \\
Croatia & 4156 \\
Czech Republic & 4298 \\
Finland & 4248 \\
Georgia & 4586 \\
Germany & 3827 \\
Honduras, Republic of & 3604 \\
Hong Kong, SAR & 3802 \\
Hungary & 5047 \\
Iran, Islamic Republic of & 5569 \\
Ireland & 4154 \\
Italy & 4013 \\
Lithuania & 4461 \\
Malta & 3397 \\
Morocco & 7401 \\
Oman & 10155 \\
Norway & 2901 \\
Poland & 4859 \\
Portugal & 3785 \\
Qatar & 4030 \\
Romania & 4485 \\
Russian Federation & 4346 \\
Saudi Arabia & 4426 \\
Singapore & 6208 \\
Slovak Republic & 5363 \\
Slovenia & 4372 \\
Spain & 4058 \\
Sweden & 4290 \\
United Arab Emirates & 14339 \\
Northern Ireland & 3331 \\
United Arab Emirates (Dubai) & 5893 \\
United Arab Emirates (Abu Dhabi) & 4100 \\
Canada (Quebec) & 3902 \\
\hline
\end{tabular}




\section{Supplementary Materials 2: Country-by-Country L1 and L2 Predictive Effects}

\section{Table S2}

Country-by-Country Estimates and Standard Errors for Student Achievement Predicting Enjoyment, From Two-Level Models Presented in Main Text Forest Plots.

\begin{tabular}{|c|c|c|c|c|c|c|}
\hline \multirow[b]{2}{*}{ Country } & \multicolumn{2}{|c|}{ Math } & \multicolumn{2}{|c|}{ Science } & \multicolumn{2}{|c|}{ Reading } \\
\hline & $\beta$ & $\mathrm{SE}$ & $\beta$ & SE & $\beta$ & $\mathrm{SE}$ \\
\hline Azerbaijan, Republic of & $.088 *$ & .015 & $.070^{*}$ & .030 & $.134^{*}$ & .027 \\
\hline Australia & $.204^{*}$ & .028 & $.114^{*}$ & .035 & $.356^{*}$ & .030 \\
\hline Austria & $.212 *$ & .040 & .075 & .041 & $.301 *$ & .048 \\
\hline Botswana & $.121 *$ & .030 & $.234^{*}$ & .023 & $.287 *$ & .029 \\
\hline Chinese Taipei & $.347 *$ & .033 & $.104^{*}$ & .033 & $.273 *$ & .032 \\
\hline Croatia & $.201 *$ & .040 & -.071 & .046 & $.238 *$ & .048 \\
\hline Czech Republic & $.173 *$ & .042 & .045 & .044 & $.301 *$ & .039 \\
\hline Finland & $.223 *$ & .036 & $.092 *$ & .043 & $.511 *$ & .033 \\
\hline Georgia & $.099 *$ & .017 & $.082 *$ & .028 & $.109 *$ & .025 \\
\hline Germany & $.244^{*}$ & .043 & $.207^{*}$ & .049 & $.345^{*}$ & .034 \\
\hline Honduras, Republic of & .043 & .029 & .014 & .034 & $.064 *$ & .030 \\
\hline Hong Kong, SAR & $.314^{*}$ & .039 & $.210^{*}$ & .048 & $.315^{*}$ & .037 \\
\hline Hungary & $.285^{*}$ & .027 & $.167 *$ & .045 & $.349 *$ & .030 \\
\hline Iran, Islamic Republic of & $.089 *$ & .019 & $.088 *$ & .021 & $.104 *$ & .021 \\
\hline Ireland & $.148 *$ & .041 & $.108 *$ & .035 & $.223 *$ & .028 \\
\hline Italy & $.203^{*}$ & .032 & $.093 *$ & .040 & $.223^{*}$ & .032 \\
\hline Lithuania & $.254^{*}$ & .029 & .009 & .029 & $.131 *$ & .032 \\
\hline Malta & $.175^{*}$ & .031 & $.120 *$ & .033 & $.185 *$ & .027 \\
\hline Morocco & $.053 *$ & .017 & $.040 *$ & .016 & $.123 *$ & .020 \\
\hline Oman & $.100 *$ & .013 & $.112 *$ & .011 & $.154^{*}$ & .015 \\
\hline Norway & $.104 *$ & .043 & .086 & .045 & $.310^{*}$ & .042 \\
\hline Poland & $.166^{*}$ & .027 & $.117^{*}$ & .028 & $.330 *$ & .028 \\
\hline Portugal & $.242 *$ & .034 & $.077^{*}$ & .029 & $.133^{*}$ & .027 \\
\hline Qatar & $.058 *$ & .023 & $.107 *$ & .022 & $.118^{*}$ & .023 \\
\hline Romania & $.185^{*}$ & .022 & $.092 *$ & .028 & $.169 *$ & .030 \\
\hline Russian Federation & $.227 *$ & .032 & .020 & .030 & $.179 *$ & .033 \\
\hline Saudi Arabia & $.043^{*}$ & .020 & $.082 *$ & .028 & $.095^{*}$ & .034 \\
\hline Singapore & $.275^{*}$ & .032 & $.246^{*}$ & .030 & $.262 *$ & .024 \\
\hline Slovak Republic & $.278 *$ & .028 & .009 & .033 & $.231 *$ & .033 \\
\hline Slovenia & $.153 *$ & .038 & -.041 & .037 & $.369 *$ & .033 \\
\hline Spain & $.144^{*}$ & .035 & -.021 & .039 & $.240 *$ & .035 \\
\hline Sweden & $.078 *$ & .029 & .056 & .035 & $.373 *$ & .037 \\
\hline United Arab Emirates & $.074 *$ & .014 & $.121 *$ & .015 & $.164^{*}$ & .017 \\
\hline Northern Ireland & $.146^{*}$ & .035 & $.182 *$ & .053 & $.294 *$ & .034 \\
\hline United Arab Emirates (Dubai) & $.104 *$ & .023 & $.131 *$ & .023 & $.195^{*}$ & .021 \\
\hline United Arab Emirates (Abu Dhabi) & $.061 *$ & .026 & $.131^{*}$ & .027 & $.172 *$ & .027 \\
\hline Canada (Quebec) & $.226^{*}$ & .040 & .079 & .054 & $.320 *$ & .034 \\
\hline
\end{tabular}




\section{Table S3}

Country-by-Country Estimates and Standard Errors for Class-Level Achievement Predicting Enjoyment, From Two-Level Models Presented in Main Text Forest Plots.

\begin{tabular}{|c|c|c|c|c|c|c|}
\hline \multirow[b]{2}{*}{ Country } & \multicolumn{2}{|c|}{ Math } & \multicolumn{2}{|c|}{ Science } & \multicolumn{2}{|c|}{ Reading } \\
\hline & $\beta$ & SE & $\beta$ & $\mathrm{SE}$ & $\beta$ & $\mathrm{SE}$ \\
\hline Azerbaijan, Republic of & -.013 & .027 & .051 & .042 & $.094 *$ & .040 \\
\hline Australia & $-.150 *$ & .067 & -.013 & .076 & .016 & .058 \\
\hline Austria & $-.298 *$ & .092 & $-.223 *$ & .073 & -.039 & .095 \\
\hline Botswana & -.080 & .057 & $-.070 *$ & .034 & $-.141 *$ & .056 \\
\hline Chinese Taipei & -.191 & .112 & -.042 & .143 & .166 & .109 \\
\hline Croatia & -.250 & .140 & .064 & .146 & -.011 & .144 \\
\hline Czech Republic & -.195 & .100 & $-.258 *$ & .129 & -.035 & .094 \\
\hline Finland & $-.296 *$ & .115 & -.192 & .133 & $-.213 *$ & .094 \\
\hline Georgia & $-.104 *$ & .031 & -.089 & .058 & $-.173 *$ & .052 \\
\hline Germany & $-.473 *$ & .104 & $-.423 *$ & .088 & -.112 & .082 \\
\hline Honduras, Republic of & $-.387 *$ & .064 & -.090 & .050 & $-.457 *$ & .069 \\
\hline Hong Kong, SAR & -.131 & .078 & -.075 & .108 & $.197 *$ & .096 \\
\hline Hungary & $-.269 *$ & .058 & $-.239 *$ & .074 & $-.181 *$ & .066 \\
\hline Iran, Islamic Republic of & $-.192 *$ & .041 & $-.103 *$ & .031 & $-.181 *$ & .037 \\
\hline Ireland & $-.204 *$ & .086 & .114 & .088 & .085 & .069 \\
\hline Italy & -.144 & .077 & $-.220 *$ & .087 & -.097 & .082 \\
\hline Lithuania & $-.166^{*}$ & .063 & -.097 & .068 & -.023 & .080 \\
\hline Malta & .098 & .086 & .012 & .079 & -.022 & .063 \\
\hline Morocco & .028 & .037 & .051 & .036 & .026 & .046 \\
\hline Oman & -.016 & .025 & $-.074 *$ & .026 & $-.071 *$ & .035 \\
\hline Norway & .111 & .102 & .169 & .137 & $.232 *$ & .107 \\
\hline Poland & $-.143 *$ & .061 & $-.341 *$ & .077 & $-.153 *$ & .069 \\
\hline Portugal & -.012 & .063 & -.125 & .065 & -.011 & .071 \\
\hline Qatar & -.075 & .042 & $-.105 *$ & .040 & .016 & .040 \\
\hline Romania & $-.242 *$ & .044 & $-.161 *$ & .050 & $-.240^{*}$ & .051 \\
\hline Russian Federation & $-.254 *$ & .057 & -.067 & .068 & -.023 & .073 \\
\hline Saudi Arabia & -.002 & .044 & -.050 & .056 & $-.124 *$ & .058 \\
\hline Singapore & -.036 & .045 & $-.291 *$ & .043 & $-.088^{*}$ & .036 \\
\hline Slovak Republic & $-.322 *$ & .059 & $-.175^{*}$ & .071 & .062 & .072 \\
\hline Slovenia & $-.328 *$ & .111 & -.166 & .111 & -.016 & .101 \\
\hline Spain & -.070 & .096 & $-.205^{*}$ & .092 & -.147 & .094 \\
\hline Sweden & $-.318 *$ & .084 & $-.188 *$ & .086 & $-.184 *$ & .086 \\
\hline United Arab Emirates & $-.121 *$ & .023 & $-.088 *$ & .025 & $-.074 *$ & .026 \\
\hline Northern Ireland & -.091 & .103 & .136 & .118 & $.308^{*}$ & .097 \\
\hline United Arab Emirates (Dubai) & $-.160 *$ & .033 & $-.094 *$ & .035 & $-.085^{*}$ & .032 \\
\hline United Arab Emirates (Abu Dhabi) & $-.117 *$ & .045 & $-.125 *$ & .052 & $-.130 *$ & .047 \\
\hline Canada (Quebec) & -.141 & .106 & -.090 & .130 & -.070 & .099 \\
\hline
\end{tabular}

